\section{Brote de encefalitis equina venezolana}

\author{
Alfonso Ruiz ${ }^{1}$
}

1 Programa de Salud Pública Veterinaria, División de Prevención y Control de Enfermedades Transmisibles, Organización Panamericana de la Salud. Dirección postal: 525 Twenty-third Street, NW, Washington, DC 20037, Estados Unidos de América.
La encefalitis equina venezolana es una enfermedad que afecta a caballos, mulas y burros y es causada por un alfavirus que solo se encuentra en la Región de las Américas. Este virus puede transmitirse a las personas por medio de la picadura de mosquitos $\mathrm{y}$, ocasionalmente, causar epizootias $\mathrm{y}$ epidemias.

Mediante pruebas serológicas, el virus de la encefalitis equina venezolana se ha clasificado en seis subtipos (cuadro 1). El subtipo I comprende siete variantes reconocidas, entre las que se incluye la cepa vacunal TC-83. Las variantes A, B y C del subtipo I son la causa principal de las epizootias y epidemias de esta enfermedad (1).

\section{ANTECEDENTES}

Desde el aislamiento del virus de la encefalitis equina venezolana en 1938 en el Estado Aragua, Venezuela, se han notificado diversos brotes, epizootias y epidemias en las Américas.

El virus ha causado epizootias y epidemias en 12 países de la Región: Colombia, Costa Rica, Ecuador, El Salvador, los Estados Unidos de América, Guatemala, Honduras, México, Nicaragua, Perú, Trinidad y Tabago, y Venezuela. Entre 1935 y 1961, se notificaron brotes en 11 años, buena parte de los cuales se produjeron en Colombia y Venezuela, aunque también se registraron en Trinidad y Tabago y en Perú.

Entre 1962 y 1973 se produjeron brotes todos los años excepto en 1965. La mayor epizootia y epidemia, que fue causada por la variante B del subtipo I, se inició en Colombia en 1967 y se extendió a Ecuador, Venezuela, América Central, México y, finalmente, alcanzó el estado de Texas en 1971. Durante esta epizootia, fallecieron de 38000 a 50000 équidos. En Ecuador se notificaron cerca de 31000 casos y 310 óbitos en personas, y en Colombia, 200000 casos $(2,3)$.

Tras esa epidemia, la vigilancia de la encefalitis equina ha disminuido en la mayor parte de los países de América Latina y el Caribe, sobre todo en los últimos 18 años. Los pocos países que notificaron casos clínicos compatibles con encefalitis equina no obtuvieron confirmación alguna de laboratorio. En América Latina y el Caribe, el diagnóstico de laboratorio de la encefalitis equina prácticamente ha cesado. 
CUADRO 1. Clasificación del complejo vírico de la encefalitis equina venezolana

\begin{tabular}{|c|c|c|c|c|}
\hline Subtipo & Variante & $\begin{array}{c}\text { Cepa } \\
\text { representativa }\end{array}$ & Actividad & Origen \\
\hline \multirow[t]{7}{*}{ I VEE } & A & TC 83 & Vacunal & Derivada de burro, Trinidad \\
\hline & A & Burro Trinidad & Epizoótica & Burro, Trinidad \\
\hline & B & MF-8 & Epizoótica & Humano, Honduras \\
\hline & C & P-676 & Epizoótica & Caballo, Venezuela \\
\hline & D & 3380 & Epizoótica & Humano, Panamá \\
\hline & $\mathrm{E}$ & Mena II & Enzoótica & Humano, Panamá \\
\hline & $\mathrm{F}$ & $78 V-3531$ & Enzoótica & Mosquitos, Brasil \\
\hline II Everglades & & Pe-3-7c & Enzoótica & Mosquitos, Brasil \\
\hline \multirow[t]{3}{*}{ III Mucambo } & A & Mucambo & Enzoótica & Mono, Brasil \\
\hline & B & Tonate & Enzoótica & Ave, Guayana Francesa \\
\hline & C & 71D-1252 & Enzoótica & Mosquitos, Perú \\
\hline IV Pixuna & & Pixuna & Enzoótica & Mosquitos, Brasil \\
\hline V Cabassou & & Cabassou & Enzoótica & Mosquitos, Guayana Francesa \\
\hline VI & & AG-80-663 & Enzoótica & Mosquitos, Argentina \\
\hline
\end{tabular}

Fuente: San Martín C. Encefalitis equinas ocasionadas por virus transmitidos por artrópodos. Bogotá: Instituto Colombiano Agropecuario; 1992.

Algunos países han continuado utilizando el sistema de información semanal del Centro Panamericano de Fiebre Aftosa (PANAFTOSA), que notifica por cuadrantes la aparición de síndromes compatibles con la encefalitis equina de origen vírico, localizando el lugar de aparición en las coordenadas cartesianas de cada país.

En el cuadro 2 se presenta un resumen de la información recibida de los países durante el período comprendido entre 1989 y 1994. La participación limitada de los países es evidente, ya que solo se han notificado datos en Argentina, Bolivia, Brasil, Colombia, Ecuador, El Salvador, Guatemala, Paraguay y Venezuela. En 1994, Perú inició la notificación $(4,5)$.

Con la escasa información ofrecida entre octubre de 1989 y diciembre de 1994, ha sido posible confirmar la existencia de áreas enzoóticas en varios países donde a menudo se notifican episodios clínicos de encefalitis equina.

\section{BROTE DE ENCEFALITIS EQUINA VENEZOLANA DE 1995}

El brote de encefalitis equina venezolana que se produjo en Venezuela y Colombia en 1995 se originó como consecuencia de un aumento de la actividad vírica en las áreas donde la enfermedad se había observado desde 1993 en una población de équidos susceptibles. Lamentablemente, en brotes previos no se habían tipificado virus de la encefalitis equina a causa de la carencia de servicios de diagnóstico de laboratorio.

CUADRO 2. Número de focos notificados de síndromes compatibles con encefalitis equina y número de semanas notificadas por país y año

\begin{tabular}{|c|c|c|c|c|c|c|}
\hline \multirow[b]{2}{*}{ País } & \multicolumn{6}{|c|}{ Año } \\
\hline & 1989 & 1990 & 1991 & 1992 & 1993 & 1994 \\
\hline Argentina & $0 / 10$ & $2 / 52$ & $3 / 52$ & $\ldots$ & $\ldots$ & $\ldots$ \\
\hline Bolivia & $\ldots$ & $6 / 31$ & $0 / 49$ & $0 / 52$ & $0 / 52$ & $0 / 46$ \\
\hline Brasil & $0 / 2$ & $8 / 41$ & $3 / 41$ & 4/52 & $3 / 49$ & $2 / 52$ \\
\hline Colombia & $2 / 13$ & $11 / 52$ & $8 / 53$ & $28 / 532$ & $7 / 52$ & $19 / 52$ \\
\hline Ecuador & $\ldots$ & $\ldots$ & $0 / 20$ & $0 / 52$ & $1 / 52$ & $0 / 52$ \\
\hline El Salvador & $\ldots$ & $10 / 9$ & $11 / 19$ & $23 / 24$ & $7 / 27$ & $\ldots$ \\
\hline Guatemala & $0 / 1$ & $1 / 36$ & $8 / 53$ & $3 / 46$ & $2 / 52$ & $0 / 51$ \\
\hline Panamá & $\ldots$ & $\ldots$ & $\ldots$ & $\ldots$ & $\ldots$ & $\ldots$ \\
\hline Paraguay & $0 / 9$ & $0 / 21$ & $0 / 52$ & $0 / 50$ & $0 / 52$ & $0 / 52$ \\
\hline Perú & $0 / 9$ & $0 / 21$ & $0 / 52$ & $0 / 50$ & $0 / 52$ & $0 / 52$ \\
\hline Venezuela & $0 / 5$ & $2 / 49$ & $0 / 46$ & $4 / 52$ & $7 / 52$ & $0 / 52$ \\
\hline
\end{tabular}

Fuente: Centro Panamericano de Fiebre Aftosa, Rio de Janeiro, Brasil. 


\section{El brote de Venezuela}

Entre diciembre de 1992 y enero de 1993, los oficiales de salud de Venezuela notificaron un brote de encefalitis equina venezolana en el Estado Trujillo. En total se registraron 28 casos clínicos y 12 muertes en équidos. Las localidades afectadas fueron: La Catalina, Zapatero, La Urbina Río Seco, Agua Caliente y Albaricol, todas ellas cercanas a la presa de Agua Viva, que se llenó en agosto de 1992. También se notificaron 39 casos febriles en personas. En esta ocasión, el aislamiento del virus de la encefalitis equina venezolana mostró la presencia del subtipo enzoótico IC $(6,7)$. En junio de 1993, también se registraron brotes en el Estado Zulia, que afectaron a 55 personas y 66 équidos. Tras estos brotes, se lanzaron campañas de vacunación en los estados occidentales de Venezuela. Desde 1994 no se han declarado brotes.

El 23 de mayo de 1995, se notificó un síndrome compatible con encefalitis equina en las localidades de Cacique Manaure y Monseñor Iturriza en el Estado Falcón, que está situado al noroeste del país. Este brote se extendió hacia el noroeste y hacia el sur. La enfermedad se diagnosticó en el norte del Estado Yaracuy el 7 de junio, en las localidades de Aroa, Yumare y Socremo del municipio de Bolívar. En ese momento se comenzó a vacunar 1435 équidos en el estado aledaño de Lara. En los últimos 15 días de agosto, la notificación de caballos muertos y enfermos precedió a la notificación de 9 casos en personas del municipio de Urdaneta, en el noreste del Estado Lara. En la investigación realizada se detectaron 15 casos sospechosos en personas y 29 équidos muertos (6). La enfermedad se propagó hacia el norte del Estado Lara y hacia el norte del Estado Falcón en dirección al lago Maracaibo, y alcanzó la vertiente oriental del Estado Zulia a fines de agosto.

La enfermedad se notificó por primera vez el 28 de agosto en la zona oriental del Estado Zulia y afectó a los distritos de Mara y Páez, localizados al noroeste del lago Maracaibo. En estos distritos se notificó la mayor parte de los casos febriles en personas (8).

El virus se aisló en el Instituto Nacional de Higiene y, posteriormente, se tipificó en las universidades de Texas y Yale, donde se identificó la variante $C$ del subtipo $I(9,10)$.

En septiembre se declararon brotes en el Estado Carabobo, en los cuales se observó un aumento de la incidencia de casos febriles en personas. El virus se aisló en dos personas enfermas (11).

En octubre, se notificaron y confirmaron aislamientos del virus que causó la enfermedad y la muerte de équidos en dos estados más: Cojedes y Guarico. En resumen, la extensión geográfica de la epizootia y epidemia de Venezuela abarcó siete estados: Zulia (50\% de su territorio), Falcón (100\%), Lara (15\%), Yaracuy (100\%), Carabobo (15\%), Cojedes (menos de 5\%) y Guarico (brote reciente) (12).

Desde el inicio de la epidemia hasta el 31 de octubre, las autoridades nacionales habían notificado 11390 casos febriles en personas compatibles con encefalitis equina venezolana y 16 muertes. La enfermedad se ha confirmado en 185 personas mediante el aislamiento del virus o la prueba de hemaglutinación-inhibición. También se han notificado cerca de 500 casos clínicos en équidos y la muerte de 475 animales, incluyendo caballos, mulas y burros (cuadro 3$)(8,12)$.

La encefalitis equina venezolana fue más grave en el Estado Zulia, donde causó 10000 casos en personas, algunos de ellos en la ciudad de Maracaibo, y 272 casos en équidos.

CUADRO 3. Casos de encefalitis equina venezolana en personas y en équidos notificados en Venezuela durante el brote de esta enfermedad en $1995^{\mathrm{a}}$

\begin{tabular}{|c|c|c|c|c|c|c|}
\hline \multirow[b]{2}{*}{ Estado } & \multirow[b]{2}{*}{$\begin{array}{c}\text { Fecha del } \\
\text { primer informe }\end{array}$} & \multicolumn{3}{|c|}{ Casos en personas } & \multicolumn{2}{|c|}{ Casos en équidos } \\
\hline & & Sospechosos & Confirmados & Muertes & Casos clínicos & $\begin{array}{c}\text { Animales } \\
\text { muertos }\end{array}$ \\
\hline Falcón & $23 / 5$ & 555 & 38 & 1 & 86 & 1 \\
\hline Yaracuy & $10 / 6$ & 73 & 3 & 2 & 56 & 1 \\
\hline Lara & $23 / 7$ & 173 & 26 & - & 82 & 1 \\
\hline Zulia & $28 / 8$ & 10,558 & 116 & 13 & 272 & 1 \\
\hline Carabobo & $10 / 9$ & 31 & 2 & - & - & 1 \\
\hline Cojedes & $10 / 10$ & - & - & - & 6 & 1 \\
\hline Guarico & $23 / 10$ & - & - & - & 2 & 1 \\
\hline Total & & 11390 & 185 & 16 & 504 & 475 \\
\hline
\end{tabular}

a Datos disponibles hasta el 31 de octubre de 1995. 
A continuación, se describen las medidas de control adoptadas.

1. Cuarentena en los estados afectados: Zulia, Falcón, Yaracuy, Carabobo, Cojedes y Guarico. Esta cuarentena condujo a la restricción del movimiento de solípedos dentro y fuera de los estados.

2. Vacunación de équidos. Desde el inicio de la epizootia, se han vacunado 163214 équidos (caballos, mulas y burros), cifra que representa $69,3 \%$ de la población de estos animales en los estados afectados y un total de 206208 équidos en el país $(27,4 \%)(11,12)$.

3. Fumigación con insecticidas para el control del vector.

4. Atención médica de las personas con fiebre. El tratamiento ha sido sintomático. Los pacientes con signos neurológicos se han hospitalizado.

\section{Brote de la encefalitis equina en Colombia}

Durante la primera semana de septiembre, los servicios rurales de salud de las localidades de Mayapo, Manaure y El Pájaro del Departamento de la Guajira notificaron un aumento del número de pacientes con fiebre, cefalea, mialgias, postración y vómitos. Pocos pacientes tuvieron convulsiones $\mathrm{u}$ otros signos neurológicos.

La enfermedad se propagó hacia el sudoeste, siguiendo sobre todo la orilla del mar Caribe y bordeando los límites con Venezuela. Una barrera natural, la Sierra Nevada de Santa Marta, evitó la diseminación directa meridional y, junto con las vacunaciones llevadas a cabo en esa zona, ayudó a crear una barrera inmune preventiva para los departamentos de Magdalena y El César. Los casos y muertes de équidos precedieron la epidemia de casos febriles en personas.

Desde el principio de la epidemia hasta el 31 de octubre, la enfermedad estuvo confinada al depar- tamento de La Guajira, excepto por la aparición de un brote reciente en équidos en la localidad norteña de Guachaca, que se encuentra en el departamento de Magdalena $(9,13)$.

Hasta el 31 de octubre, se habían notificado 14156 casos en personas compatibles con la encefalitis equina venezolana. De ellos, 1258 requirieron hospitalización y 26 fallecieron como consecuencia de la enfermedad (cuadro 4) $(3,14)$.

Los resultados de una encuesta aleatoria llevada a cabo en los hospitales de Manaure, Riohacha, Uribia y Maicao mostraron que se habían afectado personas de todos los grupos de edad. La tasa de letalidad estimada fue $0,7 \%$, y solo $4 \%$ de los pacientes con enfermedad aguda desarrollaron síntomas neurológicos, fundamentalmente niños $(7,13)$.

Las medidas de control tomadas en Colombia fueron las siguientes.

1. Se prestó atención médica de urgencias a las personas enfermas para evitar su fallecimiento, movilizando médicos, enfermeras y voluntarios de la Cruz Roja. Ello sirvió de apoyo a las tareas del personal de salud local. Asimismo, se administró tratamiento sintomático y los pacientes con signos neurológicos fueron hospitalizados.

2. Se restringió la movilidad de équidos dentro y fuera del departamento de La Guajira. Las ferias $\mathrm{y}$ actividades deportivas que se organizaron con ganado equino se suspendieron en el resto del país.

3. Se vacunaron équidos. Las autoridades nacionales notificaron la vacunación de 29700 caballos, mulas y burros en La Guajira, lo que representa casi la totalidad de la población de estos animales (96,0\%). Asimismo, las autoridades administraron vacunas en el resto del país. En total se registraron 860000 vacunaciones, cifra que representa $59,6 \%$ de la población de équidos del país (Cárdenas C, comunicación personal, 1995) (15).

4. Se llevaron a cabo tareas de control del vector. Las encuestas entomológicas realizadas en las

CUADRO 4. Datos de mortalidad y morbilidada del brote de encefalitis equina venezolana en el departamento de La Guajira, Colombia, en 1995

\begin{tabular}{lcccrc}
\hline Localidad & $\begin{array}{c}\text { Fecha del } \\
\text { primer } \\
\text { informe }\end{array}$ & $\begin{array}{c}\text { Número de } \\
\text { consultas }\end{array}$ & $\begin{array}{c}\text { Total de } \\
\text { casos } \\
\text { sospechosos }\end{array}$ & $\begin{array}{c}\text { Casos } \\
\text { hospitalizados }\end{array}$ & $\begin{array}{c}\text { Número de } \\
\text { defunciones }\end{array}$ \\
\hline Riohacha & $12 / 9$ & 5420 & 3867 & 103 & 3 \\
Maicao & $15 / 9$ & 6289 & 1362 & 68 & 8 \\
Manaure & $10 / 9$ & 12488 & 7013 & 1030 & 14 \\
Uribia & $14 / 9$ & 3945 & 1914 & 57 & 1 \\
Total & 28142 & 14156 & 1258 & 26 \\
\hline
\end{tabular}

a Datos disponibles hasta el 31 de octubre de 1995. 
zonas afectadas detectaron altas cifras de Aedes taeniorhynchus, Psorophora confinnis y Deinoceritis $s p$. Las campañas destinadas a erradicar el mosquito consistieron en fumigación con malatión y tratamiento larvicida de sus criaderos $(9,14)$.

5. Se concienció a la opinión pública a través de los medios de comunicación.

6. Se restableció la vigilancia epidemiológica de personas y équidos en el departamento afectado y en el resto del territorio del país por medio de la notificación diaria de los casos que presentaban signos compatibles con encefalitis equina.

\section{Factores asociados con la aparición del brote}

El brote de encefalitis equina venezolana de 1995 declarado en Colombia y Venezuela fue el resultado de diversos factores asociados que actuaron de forma interdependiente.

1. Disminución de la vacunación de équidos. La información reunida en las zonas afectadas de La Guajira mostró que en la mayor parte de los lugares no se había vacunado. En Venezuela, la cobertura de vacunación fue muy baja en algunos estados, como en Guarico donde solo se vacunó a 3\% de una población de 94000 équidos $(11,15)$.

2. Ausencia de vigilancia epidemiológica continua. Como se mencionó anteriormente, las actividades de vigilancia epidemiológica casi desaparecieron de los países. Los servicios de diagnóstico de laboratorio eran prácticamente inexistentes en Colombia. Esta situación disuadió al personal de los servicios de campo de enviar muestras para análisis de laboratorio (16).

La pobre coordinación intersectorial de los servicios de salud y de agricultura empeoró cuando se reestructuraron los servicios oficiales de control y vigilancia de enfermedades en los países. El deficiente intercambio de información entre los niveles locales y nacionales impidió la adopción de medidas adecuadas de prevención y control.

3. Conocimiento limitado de la ecología de las encefalitis equinas. Esta epizootia y epidemia, como otras en el pasado, estaba asociada con lluvias torrenciales e inundaciones que favorecen la reproducción de una amplia variedad de artrópodos - sobre todo mosquitos - vectores de la enfermedad. En Colombia se encontraron abundantes Psorophora sp. y Aedes taeniorhynchus y el virus de la encefalitis equina venezolana se aisló de combinaciones de sus vectores (Smith J, Ludwig G, Roberts B, USAMRIID, comunicación personal, 1995) (3).

La población de mosquitos no solo puede aumentar en condiciones climáticas favorables, sino que puede ser desplazada por corrientes de aire, inundaciones y otros fenómenos naturales $y$, de este modo, diseminar enfermedades.

Asimismo, se han reconocido otros mosquitos vectores del virus de la encefalitis equina venezolana en Colombia y Venezuela, lo cual conforma un amplio espectro de vectores que probablemente utilizan una amplia gama de huéspedes vertebrados para desarrollar sus ciclos víricos intrínsecos.

Desde la mayor epizootia y epidemia que se declaró entre 1969 y 1973, no se han descrito otros brotes importantes en la zona de Zulia, Venezuela, y La Guajira, en Colombia. Ello sugiere que las principales cepas víricas (subtipos A, B y C) se han extinguido. No obstante, el brote que se produjo en Trujillo en 1993, que fue causado por el subtipo enzoótico ID del virus de la encefalitis equina venezolana, mostró guardar una relación serológica con el subtipo IC y algún grado de homogeneidad genética (17). Estos hallazgos podrían reflejar la actividad mutagénica de los virus locales, que produciría modificaciones de su comportamiento patogénico $(7,17,18)$.

El subtipo IC del virus de la encefalitis equina venezolana aislado recientemente guarda ciertas similitudes con el subtipo IC aislado en 1963 (Smith J, et al, USAMRIID, comunicación personal, 1995).

El virus de la encefalitis equina venezolana se ha aislado en roedores considerados reservorios salvajes de la enfermedad, especialmente a consecuencia de su corta vida y alta capacidad reproductiva. Estas características podrían perpetuar la presencia del virus en una población susceptible que se renueva constantemente. Los reservorios, sobre todo los roedores que pueden mantener un ciclo enzoótico del virus de la encefalitis equina venezolana, sufren cambios en el tamaño de sus poblaciones, en la resistencia a las enfermedades, en su susceptibilidad a las enfermedades y en sus desplazamientos.

4. El aumento de la actividad vírica se notificó en brotes de baja magnitud que se produjeron en los mismos distritos, tal como lo ha notificado PANAFTOSA desde $1993(4,19)$. 


\section{REFERENCIAS}

1. San Martín C. Encefalitis equina americana por virus transmitida por artrópodos: material informativo para capacitación sobre vigilancia de las encefalitis equinas. Bogotá: Instituto Colombiano Agropecuario; 1992.

2. Acha P, Szyfres B. Zoonosis and communicable diseases common to man and animals. 2a ed. Washington, DC: Pan American Health Organization; 1987. (Scientific Publication 503).

3. Ministerio de Salud de Colombia. Encefalitis equina venezolana (EEV) en la Guajira: informe quincenal de casos y brotes de enfermedades. Bogotá: Ministerio de Salud de Colombia; 1995; 1(3):9-15.

4. Centro Panamericano de Fiebre Aftosa. Informe epidemiológico sobre encefalitis equinas, 1989-1994. Rio de Janeiro: PANAFTOSA; 1994.

5. Ruiz A. Situation of equine encephalitides in the Americas, 1989-1993. VII Inter-American Meeting at the Ministerial Level on Animal Health (VII RIMSA). Washington, DC: Pan American Health Organization; 27-29 de abril, 1993.

6. Rivera E, Ruiz L, Mosquera O, Rumbos $\mathrm{AT}$, De Vásquez H, Rangel R. Informe técnico sobre las acciones realizadas para impedir la propagación del brote de encefalitis equina venezolana al Estado de Lara, proveniente de las Entidades Falcón y Yaracuy. Barquisimeto, Venezuela: Ministerio de Agricultura y Cría; 1995.

7. Salas Mora RA. Monitoreo de la circulación de cepas enzoóticas del virus de la EEV: propuesta de investigación. Caracas:
Instituto Nacional de Higiene "Rafael Rangel"; 1994.

8. Ministerio de Salubridad y Asistencia Social, Ministerio de Agricultura y Cría, Venezuela. Reporte epidemiológico semanal para el nivel gerencial: encefalitis equina venezolana. En Alerta. Caracas: Ministerio de Salubridad y Asistencia Social, Ministerio de Agricultura y Cría; 1995, semana 39.

9. Centers for Disease Control and Prevention. Venezuelan equine encephalitis Colombia, 1995. MMWR 1995;44:721724 .

10. Ministerio de Agricultura y Cría, Dirección de Sanidad Animal. Situación de encefalitis equina en Venezuela: informe oficial. Caracas: Ministerio de Agricultura y Cría, Dirección de Sanidad Animal; 1995.

11. Ministerio de Salubridad y Asistencia Social de Venezuela: situación epidemiológica de EEV. Bol Epidemiol Semanal 1995;(43).

12. Ministerio de Salubridad y Asistencia Social, Ministerio de Agricultura y Cría, Venezuela. Reporte epidemiológico semanal para el nivel gerencial: encefalitis equina venezolana. En Alerta. Caracas: Ministerio de Salubridad y Asistencia Social, Ministerio de Agricultura y Cría, Venezuela; 1995, semana 41.

13. Ministerio de Salud de Colombia. Situación de Encefalitis Equina Venezolana: informe hasta 31 octubre, 1995. Bogotá:
Ministerio de Salud de Colombia; 6 de noviembre de 1995.

14. Ministerio de Salud de Colombia. Actualización sobre la epizoodemia de encefalitis equina venezolana: informe quincenal de casos y brotes de enfermedades. Bogotá: Ministerio de Salud de Colombia; 1995; 1(4):17-28.

15. Ruiz A. Informe de viaje a Colombia, 29 de septiembre-10 de octubre, 1995. Washington, DC: Organización Panamericana de la Salud; 1995. (Documento no publicado).

16. San Martín C. Informe final de la consultoría para la instrumentación del diagnóstico serológico en las encefalitis equinas en Colombia. Washington, DC: Organización Panamericana de la Salud; 1992.

17. Rico-Hesse R, Weaver SL, de Siger J, Medina G, Salas RA. Emergence of a new epidemic/epizootic Venezuelan equine encephalitis virus in South America. Proc Nat Acad Sci 1995;92:52785281.

18. Weaver SG, Bellew LA, Rico-Hesse R. Phylogenetic analysis of alphaviruses in the VEE complex and identification of the source of epizootic viruses. Virology 1992;191:282-290.

19. Pan American Health Organization. Situation of equine encephalitides in the Americas, 1989-1994. IX Inter-American Meeting at the Ministerial level on Animal Health (IX RIMSA). Washington, DC: PAHO/ WHO; April, 25-27, 1995. 